Shigeru Saito MD,

Yuji Kadoi MD,

Nobuhisa Iriuchijima MD,

Hideaki Obata MD,

Ken-ichi Arai MD,

Toshihiro Morita MD,

Fumio Goto MD

\section{Reduction of cerebral hyperemia with anti- hypertensive medication after electroconvulsive therapy}

Purpose: Several different anti-hypertensive regimens have been introduced for the prevention of systemic hyperdynamic responses after electrically induced seizures. In the present study, the effects of anti-hypertensive medications on cerebral circulation were studied.

Methods: Systemic blood pressure was controlled by several anti-hypertensive medications, nicardipine, prostaglandin $\mathrm{EI}$, alprenolol and nitroglycerin, in 30 patients ( 150 electroconvulsive therapy trials). Changes in cerebral blood flow velocity were measured by transcranial Doppler sonography of the right middle cerebral artery from the start of anesthesia to 10 min after the electrical shock.

Results: Administration of a $\mathrm{Ca}^{2+}$ antagonist, nicardipine, or prostaglandin $\mathrm{EI}$ did not alter the augmented cerebral blood flow velocity after the seizure. However, a ß-adrenergic blocking agent, alprenolol $(P<0.05)$ or nitroglycerin $(P<0.01)$ partially inhibited the increase in cerebral blood flow velocity. Maximal blood flow velocity was 133\% larger than the pre-anesthesia value in the control group, 109\% in the nicardipine group, 113\% in the prostaglandin EI group, $72 \%$ in the alprenolol group, and $45 \%$ in the nitroglycerin group, respectively. The increase in cerebral blood flow velocity after electrically induced seizure was independent of systemic blood pressure. Internal jugular venous saturation $\left(\mathrm{SjO}_{2}\right)$ was increased, and difference in arterial and venous concentrations of lactate was not altered in all groups.

Conclusions: Cerebral hemodynamics is altered by ECT, even when systemic hemodynamics are stabilized by antihypertensive medication. Although the effects of antihypertensive medicine on cerebral hemodynamics are variable, systemic blood pressure control by these agents does not induce cerebral ischemia after ECT.

Objectif : Différentes thérapies antihypertensives ont été proposées comme moyen de prévention des réponses hyperdynamiques généralisées à la suite d'électrochocs. Dans la présente étude, on a analysé les effets de médicaments antihypertenseurs sur la circulation cérébrale.

Méthode : La pression sanguine générale a été contrôlée par différents médicaments antihypertenseurs, la nicardipine, la prostaglandine $\mathrm{E}_{\mid}$, l'alprénolol et la nitroglycérine, chez 30 patients lors de I 50 essais d'électrochocs. Les changements de vitesse circulatoire cérébrale ont été mesurés par échographie Doppler transcrânienne de l'artère cérébrale moyenne droite, du début de l'anesthésie jusqu'à 10 min après l'électrochoc.

Résultats : L'administration d'un antagoniste de $\mathrm{Ca}_{2}+$, la nicardipine, ou la prostaglandine $\mathrm{E}_{1}$ n'ont pas modifié la vitesse circulatoire cérébrale augmentée après les convulsions. Toutefois, un agent $\beta$-bloquant, l'alprénolol $(\mathrm{P}<$ $0,05)$ ou la nitroglycérine $(P<0,0 \mathrm{I})$ ont partiellement inhibé l'augmentation de vitesse circulatoire cérébrale. La vitesse circulatoire maximale a été $133 \%$ de la valeur préanesthésique mesurée dans le groupe témoin, de 109 $\%$ dans le groupe nicardipine, de $113 \%$ dans le groupe prostaglandine $\mathrm{E}_{1}$, de $72 \%$ dans le groupe alprénolol et de $45 \%$ dans le groupe nitroglycérine, respectivement. L'augmentation de la vitesse circulatoire cérébrale à la suite d'électrochocs a été indépendante de la pression sanguine générale. La saturation en oxygène de la veine jugulaire interne $\left(\mathrm{SjO}_{2}\right)$ a été augmentée et les différences de concentration artérielle et veineuse de lactate n'ont pas été modifiées, dans aucun groupe.

Conclusion : L'hémodynamie cérébrale est modifiée par l'électrochoc, même quand la stabilité de l'hémodynamie générale est conservée par une médication antihypertensive. Quoique les effets des antihypertenseurs sur I'hémodynamie cérébrale soient variables, la pression sanguine contrôlée par ces médicaments n'induit pas d'ischémie cérébrale après l'électrochoc.

From the Department of Anesthesiology \& Reanimatology, Gunma University School of Medicine, 3-39-22, Showamachi, Maebashi, 371-8511, Japan.

Address correspondence to: Shigeru Saito MD. Phone: +81-27-220-8454; Fax: +81-27-220-8473; E-mail: shigerus@news.sb.gunma-u.ac.jp Accepted for publication April 17, 2000. 
S

EIZURE induces abrupt changes both in systemic and cerebral hemodynamics. The systemic hyperdynamic response was thought to originate from sympathetic stimulation and excessive catecholamines release. ${ }^{1}$ Cerebral hyperemia was considered to be a result of increased brain metabolism and by the augmented perfusion pressure, secondary to the high systemic blood pressure. It is difficult to study the fundamental mechanism of the cerebral circulatory changes in man, because it is ethically unacceptable to evoke seizure attacks in humans.

Electroconvulsive therapy (ECT) is prescribed for patients suffering from depression or other types of psychological disorders resistant to drug therapy. This type of therapeutic convulsion also induces abrupt changes in systemic and cerebral hemodynamics, comparable to other types of seizure. The use of muscular relaxants and management by anesthesiologists has made the therapy safe and reliable. ${ }^{1-2}$ This treatment is an appropriate clinical model for the investigation of the cerebral circulatory physiology of seizure.

Complications secondary to the hemodynamic changes may be fatal and include myocardial infarction and cardiac rupture. ${ }^{3-4}$ In order to prevent the systemic hemodynamic alterations, anti-arrhythmic and antihypertensive drugs have been employed in clinical settings. ${ }^{1}$ Such drugs include sodium nitroprusside, trimethaphan, hydralazine, nitroglycerin, clonidine and propranolol. ${ }^{1,5-6}$ Although these drugs are reported to be effective in attenuating the systemic hypertensive episode, no study has examined the effect of systemic hemodynamic stabilization by antihypertensive drugs on cerebral hyperdynamics after the electrically induced seizure.

There are several reports of considerable changes in cerebral hemodynamics induced by ECT. We reported that blood flow velocity in the middle cerebral artery (MCA) is more than doubled by ECT. ${ }^{7}$ VollmerHaase et al. reported that the velocity triples after electrical shock when the measurement was performed at bilateral middle cerebral artery simultaneously. ${ }^{8}$ Using a direct measurement of cerebral blood flow by the ${ }^{133}$ Xe clearance method, Broderson et al. demonstrated cerebral hyperemia following ECT. ${ }^{9}$ We have also demonstrated temporary cerebral hyperemia after electrical shock by utilizing near-infrared spectrophotometry. ${ }^{10}$ It is important to examine to what extent systemic hemodynamic stabilization influences the cerebral hemodynamic alterations after electrically induced seizure. Anti-hypertensive medication may reduce cerebral perfusion pressure excessively, so that oxygen delivery is not fulfilled. Moreover, by comparing the effects of anti-hypertensive medications with different pharmacodynamic actions, the underlying mechanism of cerebral hyperemia after seizure might be understood.

The purpose of this study was to identify the effects of anti-hypertensive medications on cerebral circulation, and determine whether systemic blood pressure reduction by the antihypertensive medications disturb the cerebral oxygen demand supply relationship after ECT. We measured MCA flow velocity by transcranial Doppler sonography in ECT patients, and analyzed how pretreatment with antihypertensive drugs influences the cerebral hyperdynamic response after electrical shock. The MCA flow velocity has been reported to reflect cerebral blood flow. ${ }^{11}$ In addition, oxygen saturation of internal jugular vein blood and blood lactate concentration were examined to assess the oxygen demand and supply relationship after electrically induced seizure under an anti-hypertensive regimen.

\section{Methods}

Following approval by the local ethics committee and after obtaining informed consent from the patients or their family, ECT was prescribed to patients suffering from endogenous depression $(n=30)$. Informed consent whether a patient entered this study protocol, was obtained separately after their decision to receive ECT. The patients ranged from 36 to $77 \mathrm{yr}$ (mean \pm SD: 58 \pm 15 ) and were in good physical health. No patient had cardiovascular or cerebrovascular complications, or drug allergies. All patients were treated more than six times (three times per week at one- or two-day intervals). Patients who showed blood pressure elevation at the first trial participated in this study. In each of the following five trials (from the second to the fifth), patients received one of the anti-hypertensive medications prior to the electrical shock (immediately after anesthesia induction) by a bolus injection. The doses of drugs were $0.08 \mathrm{mg} \cdot \mathrm{kg}^{-1}$ alprenolol (ALP), $0.01 \mathrm{mg} \cdot \mathrm{kg}^{-1}$ nitroglycerin (NTG), $0.6 \mu \mathrm{g} \cdot \mathrm{kg}^{-1}$ prostaglandin El (PGEl), $0.02 \mathrm{mg} \cdot \mathrm{kg}^{-1}$ nicardipine $(\mathrm{NC})$, or saline $(\mathrm{NN})$, respectively. The order of the anti- hypertensive treatments was determined by a random number table. Drug doses were chosen based on the literature ${ }^{6,12-13}$ and on previous clinical experience. ${ }^{14-15}$ The identities of the study drugs were unknown to all persons present at the ECT session. The data obtained during this study were analyzed later by an individual who was also unaware of treatment regimens.

\section{ECT procedures}

To avoid an unfavourable parasympathetic reflex, atropine sulfate $\left(0.01 \mathrm{mg} \cdot \mathrm{kg}^{-1}\right)$ was prescribed as premedication. ${ }^{1}$ Heart rate was monitored by electrocar- 
diography using standard lead II (ECG: Life scope 8; Nihon Koden Co. Ltd., Tokyo, Japan), and blood pressure (BP) was measured continuously at the right radial artery using a tonometric BP monitor (CBM-7000; Colin Co. Ltd., Komaki, Japan). The tc-Doppler (TC264; EME Co. Ltd., Uberlingen, Germany) probe was adjusted to detect MCA flow from the right temporal side. General anesthesia was induced with $2 \mathrm{mg} \cdot \mathrm{kg}^{-1}$ thiopental and $1 \mathrm{mg} \cdot \mathrm{kg}^{-1}$ succinylcholine. The antihypertensive drug or vehicle solution was injected immediately after the injection of succinylcholine. One minute after the injection, an electrical current was applied bilaterally at the minimal energy level. The electroshock stimulus was delivered by a trained psychologist using an ECT-stimulator (CS-1; Sakai Iryo Co. Ltd., Tokyo, Japan). The efficacy of electrical stimulation was determined by the tourniquet technique, that is, by observing convulsive movements in the distal part of the leg, around which an inflated tourniquet was set to prevent access of muscle relaxant. The $\mathrm{P}_{\mathrm{ET}} \mathrm{CO}_{2}$ and arterial blood oxygen saturation $\left(\mathrm{SpO}_{2}\right)$ were monitored by a respiration monitor (Capnomac Ultima; Datex Co. Ltd., Helsinki, Finland), and $\mathrm{P}_{\mathrm{ET}} \mathrm{CO}_{2}$ was maintained at 30-35 $\mathrm{mmHg}$ and the $\mathrm{SpO}_{2}$ (measured at left index) $>98 \%$ by manual ventilation assistance throughout the therapy. Blood samples were obtained with $23 \mathrm{G}$ needles from the femoral artery and right internal jugular vein immediately after anesthesia induction, and at two and five minutes after electrical shock. Blood gas and lactate concentration were analyzed by a blood gas and electrolyte analyzer (ABL5200EML105; Radiometer Inc., Copenhagen).

\section{Transcranial Doppler ultrasonography}

Flow velocity at the middle cerebral artery was measured using a $2 \mathrm{MHz}$ ultrasonic wave. The Doppler signals were obtained through the right temporal window at a depth of $45-55 \mathrm{~mm}$ from the surface. The signal quality was determined from the characteristic high pitched sound and from the wave form of the displayed sonogram. The pulsatility index (PI), which reflect the characteristics of blood flow, was calculated as follows;

$\mathrm{PI}=($ systolic velocity - diastolic velocity $) /$ mean velocity. ${ }^{16}$

\section{Data analysis}

Data are expressed as mean \pm SD. Data were compared using repeated measures two-way analysis of variance. A $P$ value $<0.05$ was considered statistically significant. Differences among mean values were analyzed by one-way analysis of variance with Sheffe's post-hoc method.
Results

In the absence of antihypertensive therapy, the alterations in systemic hemodynamics were consistent with previous reports. After a slight decrease in heart rate and blood pressure associated with induction of anesthesia, mean arterial pressure $(\mathrm{mBP})$ and heart rate

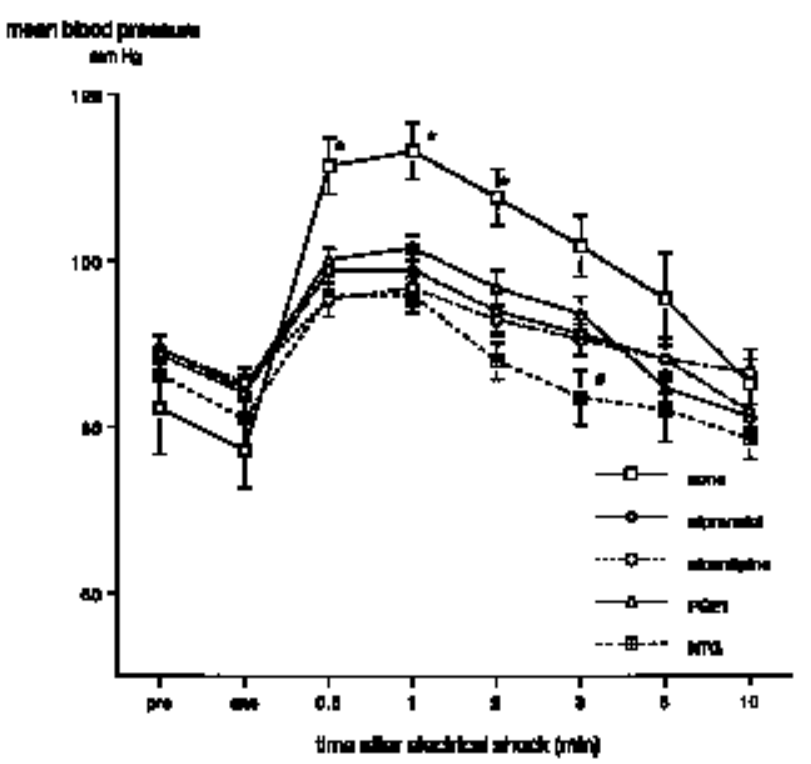

FIGURE 1 Inhibition of increase in mean arterial blood pressure by all anti-hypertensive medications tested.

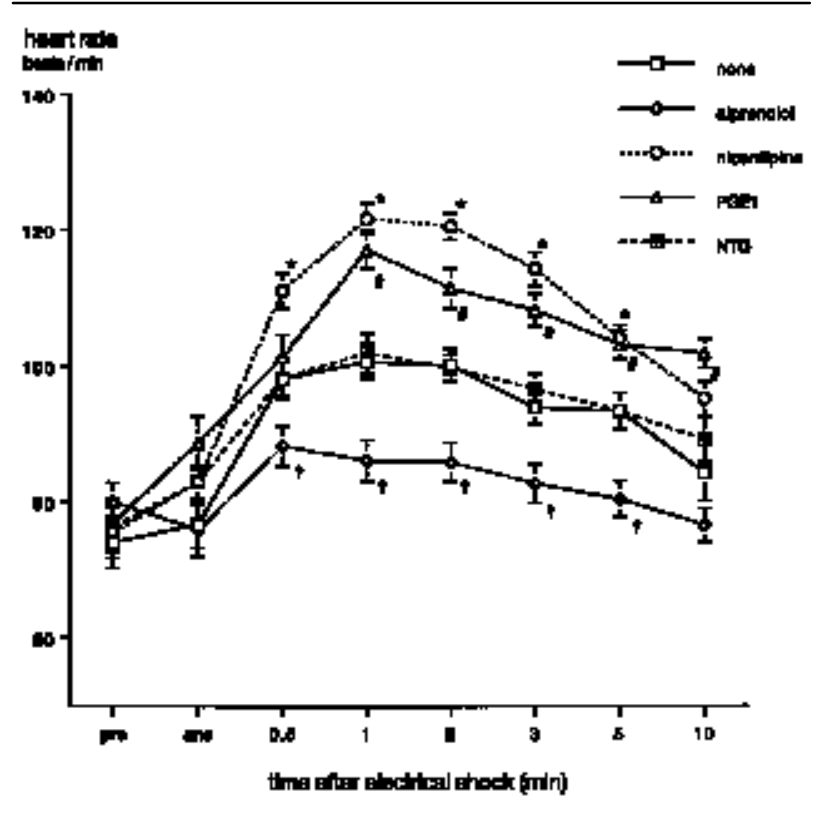

FIGURE 2 Heart rate increase modified by anti-hypertensive medication. 


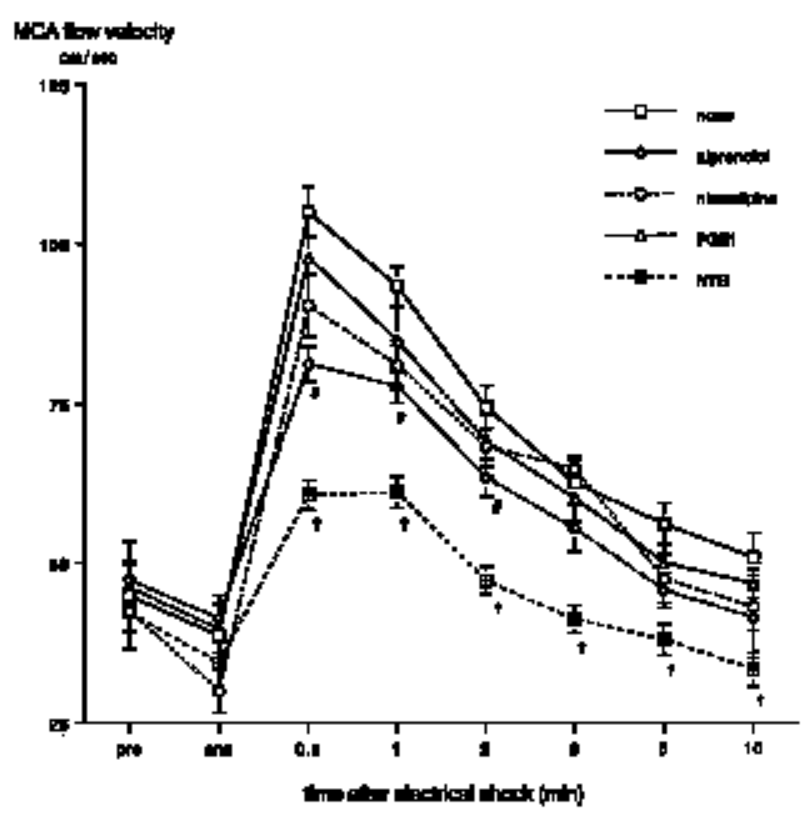

FIGURE 3 Partial inhibition of altered MCA flow velocity with alprenolol and nitroglycerin after electrical shock

(HR) were increased after electrical shock. Both circulatory variables started to increase during application of the electrical shock, reached a maximum value approximately one minute after the shock, continued for about five minutes, and returned to baseline within $10 \mathrm{~min}$. A similar overall hemodynamic pattern was observed under the anti-hypertensive medication regimens. Maximum increase in mean arterial blood pressure was $<20 \%$ of the original value in all anti-hypertensive regimens tested (Figure 1). Mean blood pressure 0.5, 1, 2 min after electrical shock was lower under anti-hypertensive regimens than under NN $(P<0.01)$. At three minutes after the shock, mBP under NTG was still less than that under NN. Heart rate was increased by approximately $30 \%$ in NN (Figure 2). This increase was augmented under NC and PGEl $(P<0.01$ at $1,2,3$ min after the electrical shock under $\mathrm{NC}$ and one minute after the shock under PGEl, $P<0.05$ at 0.5 , five minutes after the shock under NC and 2, 3, 5,10 min after the shock under PGEl). The increase under PGEl continued for more than $10 \mathrm{~min}$. Heart rate alteration under NTG was almost identical to that under NN. The HR increase was prevented by APL $(P<0.01$ at $1,2,3$, $5 \mathrm{~min}$ after the electrical shock and $P<0.05$ at $0.5 \mathrm{~min}$ after the shock).

Flow velocity at the MCA was more than doubled after electrical shock without treatment, and was not

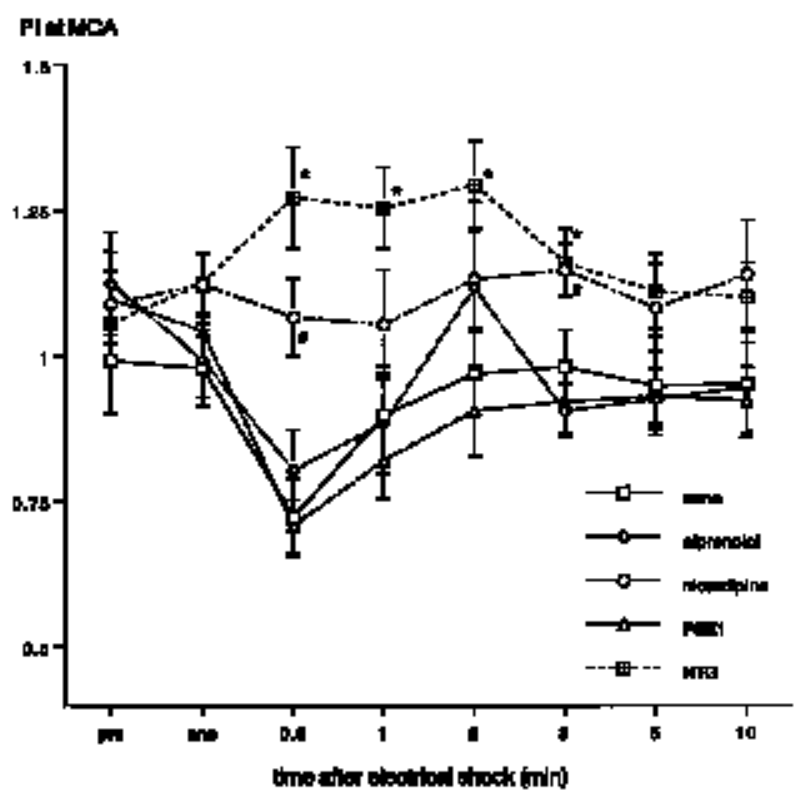

FIGURE 4 Pulsatility Index reduction prevented in the patients treated with nicardipine and nitroglycerin.

altered by NC or PGEl (Figure 3 ). This increase was partially prevented by APL and NTG $(P<0.05$ at 0.5 , 1 , two minutes after the shock under APL and $10 \mathrm{~min}$ after the shock under NTG, $P<0.01$ at $0.5,1,2,3,5$ min after the shock under NTG), but the MCA flow velocity at $0.5,1,2 \mathrm{~min}$ after the electrical shock under ALP was higher than the pre-shock value $(P<$ 0.05 at two minutes after the shock and $P<0.01$ at 0.5 , one minute after the shock). Flow velocity under NTG was higher than the pre-shock value at 0.5 , one minute after the shock $(P<0.05)$. The PI in patients without antihypertensive medication was reduced at 0.5 min after the shock and returned to the original value within one minute (Figure 4). A similar pattern was observed under APL and PGEl. However, this reduction was not observed under NC and NTG. The PI in patients treated with $\mathrm{NC}(0.5,3 \mathrm{~min}$ after the shock) and NTG $(0.5,1,2,3$ min after the shock) was larger than in untreated patients.

Oxygen saturation of internal jugular vein blood increased after ECT with all regimens (Figure 5). The increase in patients treated with NTG and PGEl was larger than in patients without antihypertensive medication $(P<0.05$ at two minutes after the shock under NTG and $P<0.01$ at 2,5 min after the shock under PGE1). Under all of regimens, lactate concentration of internal jugular vein blood increased after the 


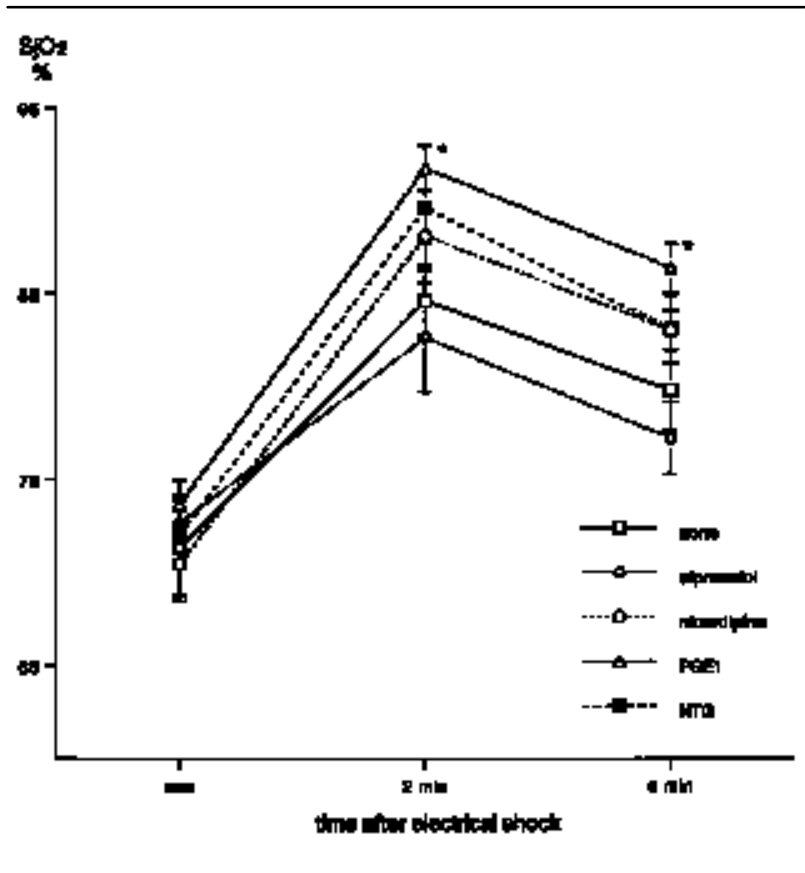

FIGURE 5 Oxygen saturation of internal jugular vein blood after electrical shock.

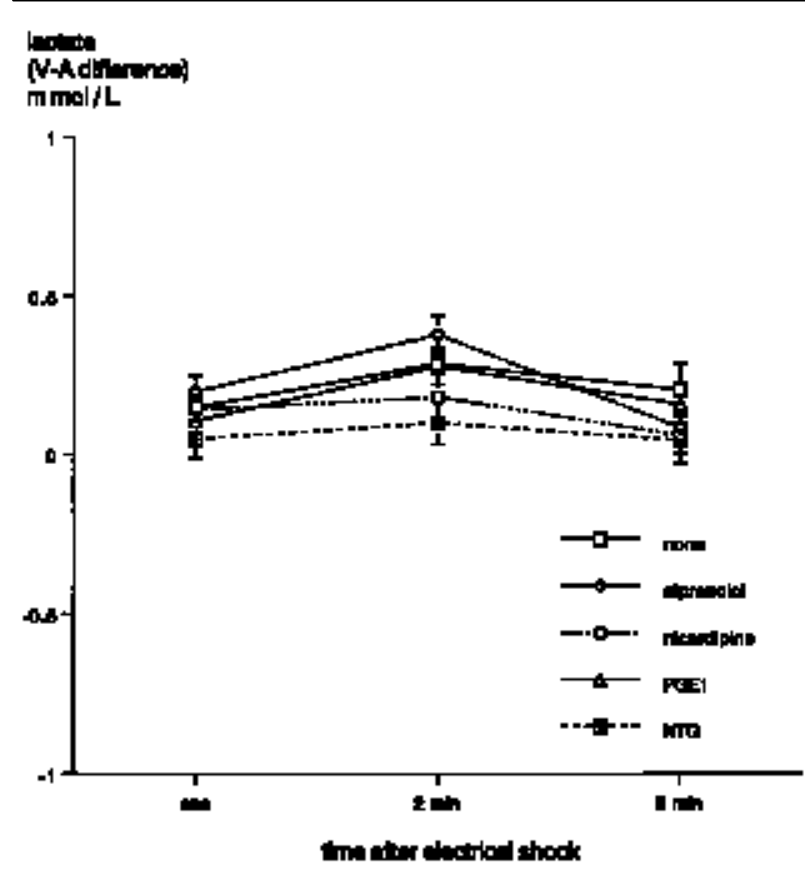

FIGURE 6 Arterial and venous lactate concentration difference was not altered by electrically induced seizure.

TAB LE Jugular vein lactate concentration

\begin{tabular}{llllll}
\hline & $N N$ & $A L P$ & $N C$ & PGEI & NTG \\
\hline pre-ECT & $1.0 \pm 0.1$ & $1.1 \pm 0.1$ & $1.0 \pm 0.1$ & $1.0 \pm 0.1$ & $1.1 \pm 0.1$ \\
One minute after ECT & $1.5 \pm 0.1$ & $1.6 \pm 0.1$ & $1.7 \pm 0.1$ & $1.5 \pm 0.1$ & $1.7 \pm 0.1$ \\
Two minutes after ECT & $1.8 \pm 0.1$ & $1.8 \pm 0.1$ & $1.9 \pm 0.1$ & $1.8 \pm 0.1$ & $1.9 \pm 0.1$ \\
\hline
\end{tabular}

Mean \pm SEM. M mol. $\mathrm{l}^{-1}$

seizure (Table). However, differences in arterial and venous concentrations were not altered by electrically induced seizure (Figure 6).

Psychological outcomes of these patients assessed by Beck depression inventory scale were not different from those of patients who did not participate in this study. No side effects of the anti-hypertensive drugs were observed.

\section{Discussion}

Effect of each anti-hypertensive drug on systemic hemodynamics

Hypertension after an electrically induced seizure has been a concern in anesthetic management of ECT. ${ }^{1}$ In the present study, we examined several anti-hypertensive medicines, which have been tested for blood pres- sure control during ECT anesthesia and reported to be effective. All four anti-hypertensive drugs effectively prevented acute blood pressure increase after electrically induced seizure and their potency on blood pressure was equivalent. The effect on heart rates was different among the drugs. The $\mathrm{Ca}^{2+}$ antagonist, nicardipine and PGEl, which have vasodilatory actions, induced tachycardia. Alternatively, the $ß$ adrenergic blocking agent, alprenolol induced relative bradycardia, potentially because of anti-chronotropism. Nitroglycerin had a minor effect on heart rates after electrically induced seizure, and this result was consistent with reports by Nurenberg and Lee. ${ }^{6,17}$

All the antihypertensive drugs tested have different pharmacological characteristics. $B$-adrenergic blocking agents prevent a hypertensive response by blocking 
adrenergic hyperdynamic action on the heart. ${ }^{18}$ Calcium antagonists dilate vessels by blocking $\mathrm{Ca}^{2+}$ entry into vascular smooth muscle cells. ${ }^{12}$ These drugs also prevent spastic vasoconstriction of cerebral arteries. ${ }^{1}$ PGEl dilates arteries via prostaglandin receptors on smooth muscle cells. ${ }^{13-14}$ Nitroglycerin is a NO donor, which relaxes smooth muscle through a cyclic GMP-dependent cascade. 6,13

Several reports describe adrenergic blocking agents as the best choice for blood pressure control during ECT, ${ }^{18}$ because activation of the adrenergic system is considered a major cause of this phenomenon. However, other anti-hypertensive medicines were also tested and reported to effectively control blood pressure. ${ }^{11,20}$ Although esmolol and labetalol are recently recommended because of their short action, we used alprenolol simply because esmolol and labetalol are not clinically available in the country where this study was performed. ${ }^{18}$ Trimethaphan and hydralazine were not examined because they have already been reported to induce prolonged hypotension after electrical shock. ${ }^{20}$

\section{Effect of each anti-hypertensive drug on cerebral hemo- dynamics}

In the present study, administration of anti-hypertensive drugs did not abolish the increase in cerebral blood flow velocity. Even after the administration of anti-hypertensive drugs, flow velocity increased 50 $150 \%$. In addition, the intensity of inhibitory effects on flow velocity increases varied among anti-hypertensive drugs, despite their similar effects on systemic blood pressure. In the present study, the cerebral blood flow velocity after seizure was reduced most in the NTG group. In contrast, a $B$-adrenergic blocking agent, alprenolol, decreased the cerebral blood flow velocity temporarily. Since cerebral blood flow velocity is influenced by multiple factors, such as, cardiac output, cerebral perfusion pressure and vessel diameter, ${ }^{21}$ it seems reasonable that each drug with unique pharmacodynamics, has a distinctive effect on cerebral flow velocity.

In normal subjects, NC is reported to increase cerebral blood flow velocity. ${ }^{12}$ In contrast, $\beta$-adrenergic blocking agents decrease cerebral blood flow in experimental study. ${ }^{22}$ NTG and PGEl have minimal effects on cerebral blood flow. ${ }^{13}$ However, the results of the present study could not be explained by the known action of the drug on cerebral circulation under stable condition. Since the cerebral circulation after electrically induced seizure is thought to be different from that in normal subjects, the action of each drug can be modified by multiple factors. NC and PGEl, which act through receptors or channel proteins blocking, might not have major action on the abrupt cerebral circulatory change after electrically induced seizure. NTG, which is a nitric oxide donor and directly relaxes vascular smooth muscle, might be able to prevent cerebral blood flow velocity increase largely.

In the patients not receiving an anti-hypertensive regimen, PI decreased immediately after the electrical shock and returned to its original value within a few minutes. This observation was consistent with a recent report by Vollmer-Haase. ${ }^{8}$ Using transcranial Doppler, they also observed a reduction in PI, $30 \mathrm{sec}$ after electrical shock. Multiple factors may influence PI, such as vascular resistance or cardiac output However, this decrease of PI is considered to indicate dilatation of small resistance arteries. ${ }^{8}$ In the present study, NC and NTG altered this pattern. Augmented pulsatility in the systemic circulation and an increase in intracranial pressure, ${ }^{14,16}$ may be related to this action by NC and NTG. Zenette et al. and Micieli et al. demonstrated that PI was unchanged by NTG administration in healthy volunteers under stable conditions. ${ }^{23-24}$ The difference between our results and theirs may be explained because our patients had sympathetic stimulation by ECT and vasodilative action of thiopental sodium, simultaneously.

\section{Oxygen demand and supply ratio after ECT}

In this study, internal jugular venous saturation $\left(\mathrm{SjO}_{2}\right)$ was increased, and the difference in arterial and venous concentrations of lactate was not altered in all groups. The $\mathrm{SjO}_{2}$ reflects the oxygen demand-supply ratio in brain. ${ }^{25}$ An increase in this value indicates a surplus supply of oxygen to the brain. Results of the present study suggest that, after electrical shock, blood supply to the brain becomes excessive. Hyperemia is induced by electrical shock, ${ }^{9-10}$ and the increased flow may be a primary cause of this alteration which may also result from decreased nervous activity after electrical shock. Metabolic activity of brain is increased temporarily during electrically induced seizure and suppressed one or two minutes after the seizure. ${ }^{1,26}$ After temporary convulsive activity, the electroencephalograph shows low frequency waves implying suppressed nervous activity after the seizure.

Posner et al. demonstrated augmented cerebral metabolism during electrically induced seizures in eight patients. ${ }^{26}$ They showed that jugular venous carbon dioxide tension increased immediately after the seizure and then returned to the original value within a few minutes. Since the jugular venous oxygen tension increased in the postictal phase, they suggested that the augmented oxygen demand after the seizure must be compensated by the increased cerebral blood flow in 
the postictal phase. Our findings, in the control group, were consistent with that report. In the present study, NTG and a $\beta$-adrenergic blocking agent partially inhibited the increase in flow velocity. However, the lack of alteration in venous-arterial lactate differences and the increased jugular venous oxygen saturation suggest that cerebral blood flow may still luxurious even in the presence of these drugs. Our data suggest that the increase in cerebral blood flow after electrically induced seizure is more than sufficient for the increase in cerebral oxygen demand, and that moderate inhibition of the cerebral hyperemia after the seizure by some anti-hypertensive agents does not provoke relative ischemia or other untoward effects.

In the present study, we obtained venous blood samples from the jugular vein. For precise analysis, blood sampling from the jugular bulb by introducing a retrograde catheter under fluorographical guidance is recommended. Because blood from the brain is contaminated with extracranial blood when blood is sampled below jugular bulb. However, because of ethical problem, such invasive blood sampling was not accepted in this study. In the ECT patients, subjects are anesthetized and paralyzed. Therefore, metabolism of extracranial tissue is stable. Also, the amount of extracranial blood contamination is limited. Therefore, the alterations in jugular blood mostly reflect the cerebral metabolic change.

In conclusion, cerebral hemodynamics is altered by ECT, even when systemic hemodynamics are stabilized with antihypertensive medication. Although the effects of antihypertensive medicine on cerebral hemodynamics are variable, systemic blood pressure control does not induce cerebral ischemia after ECT. At present, information concerning the relationship between systemic hemodynamics and cerebral circulation, and the physiological mechanisms controlling cerebral circulation after electrically induced seizures, is limited. In the present study, we measured cerebral blood flow velocity at the middle cerebral artery as a parameter of cerebral blood flow. However, the changes in vascular diameter and regional heterogeneity must also be evaluated for complete understanding of cerebral hemodynamics. Further studies with more accurate real time monitoring system may be indispensable to understand the fundamental mechanism of cerebral hyperemia after seizure.

\section{References}

1 Gaines GY III, Rees DI. Anesthetic considerations for electroconvulsive therapy. South Med J 1992; 85: 469-82.

2 Simpson KH, Lynch L. Anaesthesia and electroconvulsive therapy(ECT). Anaesthesia 1998; 53: 615-7.
3 Steiner LA, Drop LJ, Castelli I, Alfille PH, Schouten R, Welch $C A$. Diagnosis of myocardial injury by real- time recording of ST segments of the electrocardiogram in a patient receiving general anesthesia for electroconvulsive therapy. Anesthesiology 1993; 79: 383-8.

4 Ali PB, Tidmarsh MD. Cardiac rupture during electroconvulsive therapy. Anaesthesia 1997; 52: 884-6.

5 Weinger $M B$, Partridge BL, Hauger R, Mirow $A$ Prevention of the cardiovascular and neuroendocrine response to electroconvulsive therapy: I. Effectiveness of pretreatment regimens on hemodynamics. Anesth Analg 1991; 73: 556-62.

6 Nurenberg JR. Intravenous nitroglycerin in the management of posttreatment hypertension during electroconvulsive therapy. J Nerv Ment Dis 1991; 179: 291-4.

7 Saito S, Yoshikawa D, Nishibara F, et al. The cerebral hemodynamic response to electrically induced seizures in man. Brain Res 1995; 673: 93-100.

8 Vollmer-Haase J, Folkerts HW, Haase CG, Deppe M, Ringelstein EB. Cerebral hemodynamics during electrically induced seizures. Neuroreport 1998; 9: 407-10.

9 Brodersen P, Paulson OB, Bolwig TG, Rogon ZE, Rafaelsen OJ, Lassen NA. Cerebral hyperemia in electrically induced epileptic seizure. Arch Neurol 1973; 28: 334-8.

10 Saito S, Miyoshi S, Yoshikawa D, Shimada H, Morita T, Kitani $\Upsilon$ Regional cerebral oxygen saturation during electroconvulsive therapy: monitoring by near-infrared spectrophotometry. Anesth Analg 1996; 83: 726-30.

11 Caplan LR, Brass LM, DeWitt LD, et al. Transcranial Doppler ultrasound: present status. Neurology 1990; 40: 696-700.

12 Kawaguchi M, Furuya H, Kurehara K, Yamada $M$. Effects of nicardipine on cerebral vascular responses to hypocapnia and blood flow velocity in the middle cerebral artery. Stroke 1991; 22: 1170-2.

13 Kiriyama M, Haji A, Masuda A, Ito $\Upsilon$, Takeda $R$ Effects of isoflurane on brain stem blood flow and renal sympathetic nerve activity during induced hypotension. Pharmacology 1997; 54: 232-40.

14 Kadoi Y, Saito S, Morita T, et al. The differential effects of prostaglandin $\mathrm{E}_{1}$ and nitroglycerin on regional cerebral oxygenation in anesthetized patients. Anesth Analg 1997; 85: 1054-9.

15 Kadoi $\Upsilon$, Saito S, Kunimoto F, et al. Cerebral oxygenation during prostaglandin $\mathrm{E}_{1}$ induced hypotension. Can J Anaesth 1998; 45: 860-4.

16 Lindegaard K-F, Bakke SJ, Grolimund P, Aaslid R, Huber $P$, Nornes $H$. Assessment of intracranial hemodynamics in carotid artery disease by transcranial Doppler ultrasound. J Neurosurg 1985; 63: 890-8.

17 Lee JT, Erbguth PH, Stevens WC, Sack RL. Modification of electroconvulsive therapy induced 
hypertension with nitroglycerin ointment.

Anesthesiology 1985; 62: 793-6.

18 Castelli I, Steiner LA, Kaufmann MA, et al.

Comparative effects of esmolol and labetalol to attenuate hyperdynamic states after electroconvulsive therapy.

Anesth Analg 1995; 80: 557-61.

19 Robertson RM, Robertson D. Drugs used for the treatment of myocardial ischemia. In: Hardman JG, Limbird LE (Eds.). The Pharmacological Basis of Therapeutics, 9th ed. New York: McGraw-Hill Inc., 1996: 759-79.

20 Selvin BL. Electroconvulsive therapy - 1987. Anesthesiology 1987; 67: 367-85.

21 Aaslid R, Markwalder T-M, Nornes H. Noninvasive transcranial Doppler ultrasound recording of flow velocity in basal cerebral arteries. J Neurosurg 1982; 57: 769-74.

22 Mayhan WG. Responses of cerebral arterioles to activation of beta-adrenergic receptors during diabetes mellitus. Stroke 1994; 25: 141-6.

23 Micieli G, Bosone D, Costa A, et al. Opposite effects of $\mathrm{L}$-arginine and nitroglycerine on cerebral blood velocity: nitric oxide precursors and cerebral blood velocity. J Neurol Sci 1997; 150: 71-5.

24 Zanette EM, Agnoli A, Cerbo R, et al. Transcranial Doppler (TCD) after nitroglycerin in migraine without aura. Headache 1991; 31: 596-8.

25 Sheinberg M, Kanter MJ, Robertson CS, Contant CF, Narayan RK, Grossman RG. Continuous monitoring of jugular venous oxygen saturation in head-injured patients. J Neurosurg 1992; 76: 212-7.

26 Posner JB, Plum F, Van Poznak A Cerebral metabolism during electrically induced seizures in man. Arch Neurol 1969; 20: 388-95. 